\title{
A Note on the Application of Analysis of Variance in Medical Research
}

\author{
KC Bhuyan* \\ Department of Statistics, Bangladesh
}

*Corresponding author: KC Bhuyan, Department of Statistics, Jahangirnagar University, Savar, Bangladesh.

Received Date: July 22, 2019

Published Date: August 12, 2019

\begin{abstract}
In medical and in any field of bioscience the social characteristics vary with respect to any of the health hazards of the investigating units. Some of the variations may be significant or insignificant. The significance of the variation is studied by observing the association of any of the health hazards with any or all of the socioeconomic variables. Significant association indicates that health hazard depends on the social character (s). Same study can be made by the application of analysis of variance if the dependent variable is quantitative. In this paper the application of analysis of variance was presented for the analysis of real data.
\end{abstract}

\section{Introduction}

Some of the data related to bioscience are socioeconomic characteristics which are associated with different types of communicable or non-communicable diseases. For example, age, height, weight, gender, marital status, religion, education, occupation, income, food habit, working conditions, smoking habit, and utilization of time are associated with many noncommunicable diseases. This phenomenon was observed in many studies, home and abroad [ 1-20], especially these characteristics were found associated with level of obesity, prevalence of diabetes and prevalence of other non-communicable diseases. The level of obesity is measured by the ratio of body weight (in $\mathrm{kg}$ ) to square of height (in $\mathrm{m}^{2}$ ). This measurement is known as body mass index (BMI) and it is a quantitative measurement. The study of association of this variable with any of the social characteristics is not possible if the variables are not classified into groups. For example, level of income and level of obesity are significantly associated [21]. Here level of obesity depends on level of income and this dependency can be studied if the values of both the variables are measured by numerical figures. In this type of analysis, the main objective is to verify whether the values of BMI vary with the variation of income and for which level(s) of income the BMI is significantly different. This type of information is not available from the study of association. This is possible if analysis of variance, one-way or multi-way, is applied. The analysis of variance helps to distinguish between the average values of BMI for any two or more levels of income. In this note one-way analysis of variance was presented to distinguish the level of BMI of children and adults of Bangladesh with respect to some social characters.

The model for this analysis is

$$
y_{i j}=M+a_{i}+e_{i j}, i=1.2 \ldots \ldots . K ; j=1,2, \ldots \ldots \ldots \ldots n_{i} \text {, where }
$$

$\mathrm{M}=$ Grand mean of the study variable,

$a_{i}=$ Effect of $\mathrm{i}$-th level of any characteristic on which study variable depends,

$\boldsymbol{e}_{i j}=$ Random component. It is assumed that this random component follows normal distribution with mean zero and common variance.

Further assumption is that ai is not random variable.

Under the assumption mentioned above the usual analysis of variance technique can be applied. It gives

Sum of squares of study variable,

$$
S=S . S(y)=\sum \sum y_{i j}{ }^{2}-C . T, S_{1}=S . S(\text { Characteristic })=\sum \frac{\mathcal{C}_{i}{ }^{2}}{n_{i}}-C . T
$$

Here $C . T=\frac{G^{2}}{N}, \mathrm{G}=$ Grand total of study variable, $\mathrm{N}=$ total number of observations $=\sum \mathrm{a}_{\mathrm{i}}$. 


\section{$\mathcal{C}_{i}=$ total of study variable for i-th characteristic.}

Now $S_{2}=S . S .($ Error $)=\left(S-S_{1}\right)$. The results can be presented in the following analysis of variance (Table $1,2 \& 3$ ).

Table 1: Anova.

\begin{tabular}{|c|c|c|c|c|c|}
\hline $\begin{array}{c}\text { Sources of } \\
\text { Variation }\end{array}$ & d.f & $\begin{array}{c}\text { Sum of } \\
\text { Squares } \mathbf{S}_{\mathbf{I}}\end{array}$ & $M . S S_{i}=\frac{S_{i}}{d \cdot f}$ & $\mathbf{F}$ & p-value \\
\hline Characteristic & $\mathrm{k}-1$ & $\mathrm{~S}_{1}$ & $\mathrm{~s}_{1}$ & & \\
\hline Error & $\mathrm{N}-\mathrm{k}$ & $\mathrm{S}_{2}$ & $\mathrm{~s}_{2}$ & & \\
\hline Total & $\mathrm{N}-1$ & & & & \\
\hline
\end{tabular}

\section{Some Results of Analysis of Variance}

In an investigation $[16,20]$ using data of 662 children and adolescents of affluent families of Bangladesh it was observed that level of obesity measured by BMI was significantly associated with some of the socioeconomic characteristics of the children and their parents. The association indicated that level of BMI was significantly different for different levels of social characteristic. This differential behavior of level of obesity was studied here using the data of BMI instead of level of obesity. The analytical results were shown below. The analysis showed that due to the change in the levels of ages of children and adolescents the levels of BMI were significantly changed. The levels of BMI were also significantly different for those children and adolescents who had parents with different levels of education. Due to the change in the levels of family income there was significant difference in the level of BMI of the children. This analysis was almost similar as it was observed in other studies $[16,20]$.

As another example the analytical results obtained from the data collected from 900 adults of Bangladesh [18,19] were presented here. This analysis indicated that the levels of BMI of the adults were significantly different according to the differences in the levels of residence, gender, age, education, occupation, income, smoking habit, marital status and prevalence of non-communicable diseases. This finding was also similar to those were observed earlier [ 18,19,22-25].

Table 2: Analysis of variance of BMI according to different social factors of Children and adolescents.

\begin{tabular}{|c|c|c|c|}
\hline Sources of Variation & d.f & Calculated F & p- value \\
\hline Residence & 2 & 2.804 & 0.061 \\
\hline Gender & 1 & 0.115 & 0.735 \\
\hline Age & 2 & 6.357 & 0.002 \\
\hline Food habit & 2 & 1.719 & 0.18 \\
\hline Utilization of time & 3 & 2.578 & 0.053 \\
\hline Taking nutritious food & 1 & 1.459 & 0.228 \\
\hline Non-communicable diseases & 3 & 2.166 & 0.091 \\
\hline Father's education & 3 & 2.65 & 0.048 \\
\hline Mother's education & 3 & 5.115 & 0.002 \\
\hline Father's occupation & 3 & 2.166 & 0.091 \\
\hline Mother's occupation & 2 & 2.691 & 0.069 \\
\hline Family income & 3 & 4.112 & 0.007 \\
\hline
\end{tabular}

Table 3: Analysis of variance of BMI according to different social factors of adults.

\begin{tabular}{|c|c|c|c|}
\hline Sources of Variation & d.f & Calculated F & p-value \\
\hline Residence & 1 & 5.002 & 0.026 \\
\hline Religion & 1 & 0.002 & 0.961 \\
\hline Gender & 1 & 22.218 & 0 \\
\hline Age & 3 & 3.503 & 0.015 \\
\hline Education & 4 & 2.715 & 0.029 \\
\hline Occupation & 4 & 6.126 & 0 \\
\hline Income & 4 & 5.656 & 0 \\
\hline Type of work & 4 & 1.089 & 0.361 \\
\hline Marital status & 1 & 4.318 & 0.038 \\
\hline Smoking habit & 1 & 5.305 & 0.021 \\
\hline Prevalence of diabetes & 1 & 1.402 & 0.237 \\
\hline Prevalence other diseases & 4 & 2.645 & 0.032 \\
\hline
\end{tabular}

\section{Acknowledgement}

None.

\section{Conflicts of Interest}

No conflicts of interest.

\section{References}

1. Berg C, Rosengren A, Aires N, Lappas G, Torén K, et al (2005) Trends in overweight and obesity from 1985-2002, Gotenberg, West Sweden. Inter Jour Obesity 29(8): 916-924.

2. Skliros EA, Merkoures P, Sotiro Poulos A, Xipnitos C, Liva H, et al (2008) The relationship between body mass index and hypertension in elderly Greeks The Nemea Primary Care Study. Jour Amer Geriatrics Soc 56(5): 954-955.

3. Kushal N (2009) Adversities of accumulation? Prevalence of obesity among immigrants. Health Economics 18(3): 291-303.

4. Prasad SB, Fahrtash F, Malaiapan Y, Meredith IT, Cameron J (2009) Obesity and metabolic syndrome in patients with acute myocardial infraction. Int Jour of Card 144(3): 450-451.

5. Redon JI, Cifkova R, Laurant S, Nilsson P, Narkiewicz K et al (2008) The metabolic syndrome in hypertension: European Society of Hypertension Position Statement. Jour of Hypertension 26(10): 1891-1900.

6. Basen Engquist $\mathrm{K}$, Chang M (2011) Obesity and cancer risk: recent review and evidence. Curr Oncol Rep 13(1): 71-76.

7. Bertino B, Ardiri AM, Ali FT, Boemi PM, Cilio D, et al (2006) Obesity and related diseases: an epidemiological study in Eastern Sicily. Minerva Gastroenterol Dietol 52(40) :379-385.

8. Pulgaron ER (2013) Child obesity: a review of increased risk for physical and psychological combordities. Clin Ther 35(1): 18-32.

9. Sinha R, FischG, Teague B, Tamborlane WV, Banyas B, et al (2002) Prevalence of impared glucose tolerance among children and adolescents with a marked obesity. N Engl J Med 346(11): 802-810.

10. Weiss R, Dziura J, Burgert TS, Temborlane WV, Taksali SE, et al (2014) Obesity and the metabolic syndrome in children and adolescents. N Engl J Med 350(23): 2362-2374.

11. Calamusa G, Amodio E, Costantino C, Maria D, Pasquate, et al (2012) Body mass index and factors associated with overweight and obesity: a cross-sectional study of adult subjects living in a small city of Western Sicily (Italy). Italian Jour Pub Health 9(3): e7539.

12. Akter S, Rahaman MM, Sarah KA, Sultan P (2014) Prevalence of diabetes and pre-diabetes and their risk factors among Bangladeshi adults: A Nationwide survey. Bulletin of the WHO 92(3): 204-213. 
13. Rahim MA, Hussain A, Azad Khan AK, Sayed MA, Keramat Ali SM, et al. (2007) Rising prevalence of type-II diabetes in rural Bangladesh: A population-based study. Diabetes Research and Clinical Practice 77(2): 300-305.

14. Rahaman S, Islam Tauhidul, Dewn S, ALAM (2014) Obesity and overweight in Bangladeshi children and adolescents: a scoping review. BMC Public Health 14: 70.

15. Biswas T, Islam A, Islam S, Pervin S, Rawal LBB (2017) Overweight and obesity among children and adolescents in Bangladesh: a sustematic review and meta-analysis. Public health 142: $94-101$.

16. Urmi AF, Bhuyan KC (2018) Identification of factors responsible for obesity in children and dolescents of some affluent families. Bimed J Sci Tech Res 10(5): 8121-8129.

17. Hoque ME, Suhail AR, Doli Munim M, Kurt L, Louis WN (2014) Prevalence of overweight and obesity among children and adolescents of the Indian sub- continent: A meta-analysis approach. Nutrition Review 72(8): 542 550 .

18. Bhuyan KC, Jannatul F (2019) Discriminating Bangladeshi adults by level of obesity. LOJ Med Sci 3(1): 184-191.

19. Bhuyan KC, Fardus J, Rahaman S(2016) Relationship between socioeconomic factors and diabetes among urban and rural people of Bangladesh. Global Journal of Quantitative Science 3.
20. Bhuyan KC (2019) Socioeconomic variables associated with level of obesity and prevalence of other diseases among children and adolescents of some affluent of Bangladesh. Archives of diabetes and Obesity 2(2): 147-154.

21. Serdula MK, Ivery D, Coates R J, Freedman DS, Williamson DS, et al (1993) Do obese children become obese adults? A Review of Literature. Prev Med 22(2): 167-177.

22. Branca F, Nikogosian H, Lobstein T, Copenhagen WHO (2007) The challenge of obesity in the WHO European region and the strategies for response.

23. Strauss RS Knigh J (1999) Influence of the home environment on the development of obesity in children. Pediatrices 103(6): 85.

24. Jannatul F, Bhuyan KC (2016) Discriminating diabetic patients of some rural and urban areas of Bangladesh: A discriminant analysis approach. Euromediterrean Bio Jour 11(9): 134-140.

25. Elizabeth R, Pulgaran ER, Alam M, Delameter (2014) Obesity and type-II diabetes in children, epidemiology and treatment. Curr Diab Rep 14(8): 508. 